\title{
The impact of nonwound site infection on surgical wound healing
}

\author{
Tsippora Shainhouse BSc, Ronald M Zuker MD FRCSC FACS FAAP \\ Division of Plastic Surgery, The Hospital for Sick Children, University of Toronto, Toronto, Ontario
}

\begin{abstract}
T Shainhouse, RM Zuker. The impact of nonwound site infection on surgical wound healing. Can J Plast Surg 1999;7(5):229-232.

When infection occurs at a surgical site, it is clear that the normal wound healing process is destroyed, interrupted or at best retarded. However, little is known about the effects of nonwound site infections on the healing process. One concern is that the level of cytokine tumour necrosis factor-alpha $(\mathrm{TNF} \alpha)$ produced in the inflammatory process of the infection will have a detrimental effect on the wound healing process. Another concern is that the negative clinical manifestations of sepsis on the maintenance of homeostasis are augmented by the effects of general anesthetic agents used in surgery. Therefore, if the infection is not minor and has the potential for systemic spread, it is best to defer surgery until the infection clears. However, in nonelective surgery, the candidacy of a surgical patient is more likely to be dependent on the clinical manifestations of the infection.
\end{abstract}

Key Words: Infection; Nonwound site; TNF $\alpha$; Wound healing

\section{L'impact d'une infection à un site anatomique non opératoire sur la cicatrisation d'une plaie opératoire}

RÉSUMÉ : Lorsqu'une infection survient au site d'une plaie opératoire, il est clair que le processus normal de cicatrisation est détruit, interrompu ou, au mieux, retardé. Cependant, les effets des infections à des sites anatomiques non opératoires sur le processus de cicatrisation sont peu connus. Il est à craindre que le niveau du TNF $\alpha$ (tumour necrosis factor-alpha), cytokine produite dans le processus inflammatoire de l'infection nuise au processus de cicatrisation. Une autre source d'inquiétude est que les manifestations cliniques négatives de la septicémie sur le maintien de l'homéostasie soient augmentées par les effets des anesthésiants généraux utilisés pendant la chirurgie. Par conséquent, si l'infection n'est pas mineure et qu'elle peut se généraliser, il vaut mieux retarder la chirurgie jusqu'à ce que l'infection se dissipe. Cependant, dans un cas de chirurgie non élective, la décision d'opérer le patient dépendra plus vraisemblablement des manifestations cliniques de l'infection.

$\mathrm{W}$ ound healing is the result of a complex synergistic series of biomolecular activity that can be altered by numerous factors. One such factor is infection. If the infection occurs at the surgical site, it is clear that the normal process is destroyed, interrupted or at best retarded. However, little is known of the effects of nonwound site infection on the healing process. This review evaluates and makes recommendations regarding the patient who presents with infection in another anatomic site, based on wound healing potential.

Correspondence and reprints: Dr Ronald M Zuker, The Hospital for Sick Children, 555 University Avenue, Room 1524, Toronto, Ontario M5G 1X8. Telephone 416-813-6447, fax 416-813-6147,

e-mail ronald.zucker@mailhub.sickkids.on.ca

\section{THE DEVELOPMENT OF WOUND SITE INFECTION}

As many as $71 \%$ of all nosocomial infections occur in surgical patients, $40 \%$ of which occur at the postoperative wound site (1). The development of wound site infection depends on several factors, including: microbial pathogenicity, local and systemic host defenses, local environmental factors and surgical technique (2). Microbial pathogenicity can be considered the balance between host defenses and microbial virulence. This balance can be tipped by bacteria that are resistant to phagocytosis and/or intracellular lysozymes, or by microbes that produce exo- or endotoxins. These toxins injure host cells directly or activate host mediators to cause damage. Local host defenses include epithelium, mucus membranes and local immunoglobulin A, whereas systemic host defenses include phagocytic cells, the humoral and cellular immune systems and molecular cascades. 
TABLE 1

Effects of tumor necrosis factor-alpha (TNF $\alpha$ )

\begin{tabular}{|c|c|}
\hline Body part/system & Effect \\
\hline Brain & $\begin{array}{l}\text { Fever, anorexia, somnolence, } \\
\text { increased CRF and ACTH, secretion }\end{array}$ \\
\hline Lungs & $\begin{array}{l}\text { Capillary leak, } \\
\text { ventilation-to-perfusion } \\
\text { mismatching, ARDS }\end{array}$ \\
\hline Heart & Myocardial depression \\
\hline Vascular endothelium & $\begin{array}{l}\text { Vasodilation(increased nitric oxide } \\
\text { production), capillary leak, } \\
\text { increased procoagulant activity }\end{array}$ \\
\hline Liver & Release of acute phase protein \\
\hline Bone & Resorption \\
\hline Adipose tissue & Increased lipolysis \\
\hline Bone marrow & Depressed erythropoiesis \\
\hline Lymphocytes & $\begin{array}{l}\text { Proliferation, enhanced } \\
\text { immunoglobulin production, } \\
\text { enhanced cytokine production }\end{array}$ \\
\hline Macrophages and monocytes & $\begin{array}{l}\text { Chemoattraction, cytotoxic } \\
\text { activation, prostaglandin } \\
\text { production, enhanced cytokine } \\
\text { production }\end{array}$ \\
\hline Neutrophils & $\begin{array}{l}\text { Enhanced cytokine production, } \\
\text { activation }\end{array}$ \\
\hline
\end{tabular}

CRF-Chronic respiratory failure; ACTH-Adenocorticotropic hormone; ARDS-Adult respiratory distress syndrome (11)

Local factors that can inhibit these defenses include the presence of devitalized tissue and foreign bodies. Two surgical techniques have been developed to reduce the risk of wound infection: the reduction of microbial inoculation into the wound site by the use of antiseptics, gloves, masks, sterile instruments and drapes, and the use of measures directed towards improving host containment and elimination of the microbes that have circumvented the former measures, for example, gentle tissue handling and avoidance of hematomas and dead space. Regimens of perioperative antimicrobial prophylaxis have been recommended for a wide variety of surgical procedures (1).

\section{THE EFFECTS OF NONWOUND SITE INFECTION OR SEPSIS IN THE SURGICAL PATIENT}

Previously mentioned measures specifically address postoperative infection of the surgical wound site. Similar consideration is applied when surgery must be performed on a site that is already infected. However, it is not uncommon for patients to present to a surgical service while harbouring a remote, nonwound site infection. The presence of remote infection has been shown to triple the rate of postoperative wound infection (2). Furthermore, the negative physiological effects associated with remote and/or systemic infections (sepsis) are compounded by effects associated with the general anesthetics necessary for surgery. Studies have revealed that the presence of remote and/or systemic infections affect surgical wound healing $(3,4,5,6)$. What follows is a description of the effects of nonwound site infection in the surgical patient. Examination of these effects should elucidate whether or not such patients are surgical candidates.

Infection with various bacteria, fungi, parasites or viruses will normally cause a mild, local inflammatory response. This response is characterized by an increase in vascular diameter, due in part to induction of endothelium to produce nitric oxide (7). The increase in vascular diameter results in increased blood flow, heat and redness at the site. There is also an increase in vascular permeability to fluid, proteins and white blood cells, causing pain and swelling, and finally an increased endothelial adhesiveness for phagocytes and platelets. These effects are mediated by the local release of the cytokine tumour necrosis factor-alpha (TNF $\alpha$ ) also known as cachectin, by activated macrophages. The pathogen is subsequently phagocytosed, and local vessel occlusion due to clotting prevents it from spreading through the bloodstream and causing widespread infection (8). Thus, mild, locally-contained infections have little, if any, distant effects.

However, when there is a systemic infection, with a pathogen that triggers the release of TNF $\alpha$, macrophages are activated throughout the body, enabling TNF $\alpha$ to potentially act in a similar manner on all blood vessels. This systemic inflammatory response syndrome (SIRS) can ultimately result in widespread organ dysfunction. SIRS is defined by the following clinical criteria: altered body temperature (greater than $38^{\circ} \mathrm{C}$ or less than $36^{\circ} \mathrm{C}$ ), tachycardia (greater than $90 \mathrm{bpm}$ ), tachypnea or hypercarbia (greater than 20 breaths/min or less than $32 \mathrm{mmHg}$ ), leukocytosis or leukopenia (greater than $12000 / \mathrm{mm}^{3}$ or less than $4000 / \mathrm{mm}^{3}$ ) or leukocyte band forms (7). The major systemic, physiological effects of TNF $\alpha$ (Table 1), include hypotension (less than $90 \mathrm{mmHg}$, in adults [9]), myocardial depression and adult respiratory distress syndrome. The most concerning result of systemically introduced TNF $\alpha$ is hypovolemic induced septic shock, and subsequent development of disseminated intravascular coagulation, which can lead to failure of vital organs such as the kidneys, liver, heart, lung and spleen (Figure 1).

Defects in the host defense system that predispose an infected individual to sepsis include the following; disruption or penetration of anatomical barriers, presence of devitalized tissue, granulocytopenia and defective granulocyte function, complement defects, immune defects and splenic malfunction or absence (9). Surgery induces systemic and local changes in the host defense system such as impaired neutrophil function and serum opsonizing capacity. It takes nine days postsurgery for neutrophil microbicidal activity to return to normal (1). In this immunosuppressed state, the surgical patient is at risk of infecting the wound site via hematogenous seeding. It is also possible to directly inoculate the wound site postoperatively with the pathogens festering at the remote infection site. Further many pathogens cause mild or transient immunosuppression during acute infection, which make the host more susceptible to secondary infections by common environmental organisms (8). Of note, the National Nosocomial Surveillance System, with regard to common environmental organisms, has demonstrated a declining pro- 
portion of Gram-negative bacterial infections, and an increasing proportion of staphylococcal and fungal infections (10). This suggests that the surgical candidate with systemic infection is already predisposed to wound site infection before even considering the transient immunosuppression associated with the surgery itself. The host defense system may be able to manage the physiological effects of remote site or systemic infection and, thus, maintain a semblance of homeostasis. However, the compound physiological effects of the general anesthesia required for most surgical procedures, together with those already experienced by the infection harbouring/septic patient, may be too overwhelming for the body to tolerate. Of the common anesthetic agents used, Thiopental is a myocardial depressant. Propofol is a hypotension inducing agent due to both the decrease in vascular resistance and myocardial depression associated with it. Ketamine is the only induction agent with stimulatory effects on the cardiovascular system, however, shock patients are still susceptible to severe hypotension even with small doses. Curare and atacurium, both muscle relaxants, can cause hypotension when given rapidly in the presence of hypovolemia, which, as delineated above, is associated with septic shock (11).

Given that the negative clinical manifestations of systemic infection are augmented by the effects of general anesthetic agents, their use in septic patients is contraindicated. However, some patients, even if septic, must have an anesthetic. What then, are the effects of the systemic infection process on surgical wound healing?

\section{THE MECHANISM OF WOUND HEALING AND THE ROLE OF TNF $\alpha$}

The mechanism of wound healing leading to wound closure, involves a sequence of discrete steps. First, induction of an acute inflammatory response to the initial trauma (for example surgical incision), then regeneration of parenchymal cells, followed by migration and proliferation of both parenchymal and connective tissue cells (fibroblasts), and synthesis of extracellular matrix proteins and finally remodeling of connective tissue (especially collagen) and parenchymal components, and acquisition of wound strength (12). The cytokine $\mathrm{TNF} \alpha$ mediates the acute phase reactions of inflammation as described above, in addition to fibroblast migration and proliferation, collagen synthesis by fibroblasts and collagenase secretion.

From the above description, it seems logical to conclude that TNF $\alpha$ plays an integral, positive role in the wound healing process. In fact, a study by Fu et al (4) demonstrated that a single dose of locally applied TNF $\alpha$ increased angiogenesis, fibroblast proliferation and collagen formation in both incisional and gunshot wounds. Yet, of the local factors, which range from nutritional deficiencies (protein,Vitamin C) to inadequate blood supply, infection, which triggers the production of TNFo, is touted as the single most important cause of delay in wound healing (12). Further, TNF $\alpha$ induces tissue injury in animals subjected to experimental sepsis (2). The questions remains as to whether TNF $\alpha$ is actually the component associated with sys-

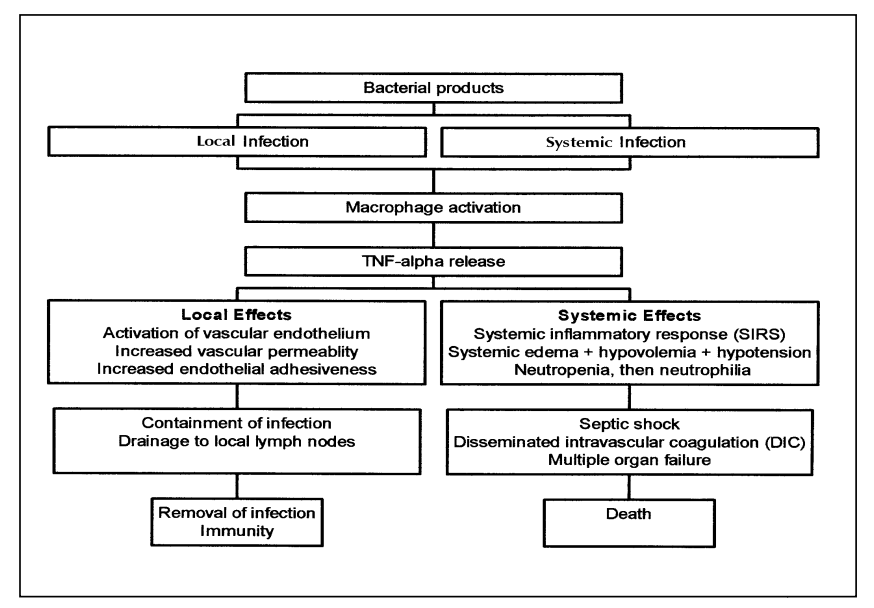

Figure 1) Local and systemic effects of tumour necrosis factor-alpha release by activated macrophages

temic infection that negatively impacts on the wound healing process, and if so, how this explains the seemingly positive impact it can have.

Recent studies $(3,5,6)$ have demonstrated that repeated application of TNF $\alpha$ to both incisional and excisional wounds inhibited the ingrowth of granulation tissue and significantly reduced the synthesis of collagen (proalpha [I], proalpha [III], 3H-hydroxyproline) compared with controls. Buck et al (3) examined the effect of chronically elevated $\mathrm{TNF} \alpha$ levels, as would be observed in patients with cachexia associated infection, inflammation and cancer. Even before the onset of cachexia, TNF $\alpha$ mice demonstrated a decrease in collagen synthesis and collagen alpha (I) mRNA in the skin, as well as impaired healing of incisional and excisional wounds. The authors suggested that TNF $\alpha$ may play an "important role in the impaired wound healing of chronic diseases that are characterized by a high production of this cytokine."

So, is TNF $\alpha$ production a self-protective or maladaptive response of the host defense system? With respect to sepsis associated TNFo, studies show that pretreatment of mice models with TNF $\alpha$ protects them from Gram-negative bacterial infection (9), however, there are also studies that support the use of monoclonal anti-TNF antibodies to treat sepsis $(13,14)$. It appears that in sepsis, "the host is fighting infection with every weapon at its command, but the deployment is so massive, that the toll from friendly fire precludes victory" (9).

On the other hand, wound-associated $\mathrm{TNF} \alpha$ may very well have a dose dependent effect. Whether the concentration of TNF $\alpha$ that reaches the surgical wound locale of a given septic patient is sufficient to impair collagen and granulation tissue formation and, hence, wound healing, is not clear. As such, elective operations should generally be delayed until the infection has been eliminated (2). If the surgery must be performed before the infection has cleared, prophylactic antibiotics are appropriate to prevent secondary infections by common environmental organisms. Ensuring that the patient is nutritionally competent (protein, Vitamin C, calories) will optimize wound 
healing. Prophylactic glucocorticoids induce an immunocompromised state. While they do inhibit inflammation and TNF $\alpha$, they also decrease host resistance to opportunistic environmental contagions and delay wound healing (fibroplasia). Some of the mainstays of sepsis treatment are maximization of oxygen delivery to the tissues, rehydration therapy, adrenergic drugs to maintain tissue perfusion pressure, increase myocardial contractility and correction of the maldistribution of circulation (9).This brings the discussion back to general anesthetics. The effects of these agents are dangerous in synergy with those attributed to sepsis. If a patient is not stable enough to undergo the anesthesia, then the issue of surgical wound healing is irrelevant.

\section{REFERENCES}

1. Kernodle DS, Kaiser AB. Postoperative infections and antimicrobial prophylaxis. In: Mandel, GL, Bennet, JE, Dolin R, eds. Principles and Practice of Infectious Diseases. New York: Churchill Livingstone, 1995.

2. Schwartz SI, Shires GT, Spencer FC, eds. Principles of Surgery, 6th edn. Toronto: McGraw-Hill, 1994.

3. Buck M, Houglum K, Chojkier M. Tumor necrosis factor-alpha inhibits collagen alpha1(I) gene expression and wound healing in a murine model of cachexia. Am J Pathol 1996;149:195-204.

4. Fu X, Tian H, Hsu S, Wang D, Sheng Z. In vivo effects of tumor necrosis factor-alpha on incised wound and gunshot wound healing. J Trauma. 1996;40:S140-3.

5. Rapala K. The effect of tumor necrosis factor-alpha on wound healing. An experimental study. Ann Chir Gynaecol Suppl 1996;211:1-53.

6. Rapala K, Peltonen J, Heino J, et al. Tumour necrosis factor-alpha selectivity modulates expression of collagen genes in rat granulation tissue. Eur J Surg 1997;163:207-14.

7. Longnecker DE, Murphy FC. Introduction to Anesthesia 5th edn. Toronto: WB Saunders, 1992:372-7.

8. Janeway CA, Travers P, eds. Immunobiology: The Immune System

\section{CONCLUSIONS}

It is not uncommon for surgical patients to present preoperatively with a secondary, nonwound site related infection, or worse, sepsis. One concern is that the level of cytokine TNF $\alpha$ produced in the inflammatory process of the infection, will have a detrimental effect on the wound healing process at the distal surgical site. Studies suggest that this might be so. Therefore, if the infection is significant and has the potential for systemic spread, it is best to defer surgery until the infection clears. However, in nonelective surgery, the candidacy of a surgical patient is more likely to be dependent on the clinical manifestations of the infection. If the patient is not stable enough to tolerate the effects of anesthesia, then the impact of sepsis on wound healing is not pertinent.

in Health and Disease, 3rd edn. New York: Current Biology Limited, 1997:13-20.

9. Schaechter M, Medoff G, Eisenstein BI, eds. Mechanisms of Microbial Disease, 2nd edn. Baltimore: Williams and Wilkins, 1992:770-8

10. Fiore AE, Joshi M, Caplan ES. Approach to infection in the multiply traumatized Patient. In: Mandel, GL, Bennet, JE, Dolin R, eds. Principles and Practice of Infectious Diseases, 4th edn. New York: Churchill Livingstone, 1995:2756-61.

11. Morgan E, Mikhail MS. Clinical Anesthesiology, 2nd edn. Stanford: Appleton and Lange, 1996:826-9.

12. Cotran RS, Kumar V, Robbins SL, eds. Pathologic Basis of Disease, 5th edn. Toronto: WB Saunders Company, 1994:35-92.

13. Tracey KJ, Fong Y, Hesse DG, et al. Anti-cachectin/TNF monoclonal antibodies prevent septic shock during lethal bacteremia. Nature 1987;330:662-4.

14. Ziegler EJ, Fisher CJ Jr, Sprung CL, et al. Treatment of gram-negative bacteremia and septic shock with HA-1A human monoclonal antibody against endotoxin. A randomized, double-blind, placebo-controlled trial. The HA-1A Sepsis Study Group. N Engl J Med 1991;324:429-36. 